\title{
O NOME PORTUNHOL E A DENOMINAÇÃO SELVAGEM: MARCAS DE RESISTÊNCIA NA E PELA LÍNGUA
}

\author{
THE PORTUNHOL NAME AND THE "SELVAGEM" \\ DENOMINATION: RESISTANCE MARKS AT AND BY THE \\ LANGUAGE
}

Gabriela Souto Alves ${ }^{1}$

\begin{abstract}
RESUMO: Regiões de fronteiras costumam ser lugares de entrecruzamento de línguas. No caso do Brasil e dos países vizinhos, efetivam-se múltiplas situações de um portunhol falado. $O$ acontecimento discursivo novo é o portunhol escrito pelo viés artístico-literário, problematizando tal questão, uma vez que a escrita parece ter o poder de legitimar essa língua marginalizada ao elevá-la ao contexto da cultura letrada. Esse portunhol da arte, denominado selvagem, como resistência, não se submete a uma regra ou gramática nos moldes normativos e totalitários estabelecidos. A questão teórica deste trabalho é especificamente o funcionamento do nome/denominação portunhol selvagem no interior de uma contraidentificação. Isso por um percurso metodológico que se inscreve na teoria materialista do discurso e que considera os gestos de interpretação como um dispositivo teórico. A materialidade envolve uma entrevista concedida pelo precursor do movimento, Douglas Diegues, em 2012. Interpreta-se como o nomear e denominar, nessa perspectiva de resistência, também identifica.
\end{abstract}

PALAVRAS-CHAVE: Portunhol Selvagem; Análise De Discurso; Resistência; Douglas Diegues.

ABSTRACT: Frontier regions are often places of intercrossing languages. In the case of Brazil and neighboring countries, there are multiple situations of a spoken portunhol. The new discursive event is the portunhol written by the artistic-literary bias, problematizing this question, since writing seems to have the power to legitimize this marginalized language by elevating it to the context of literate culture. This portunhol of art, called selvagem, as resistance, does not submit to a rule or grammar in the established normative and totalitarian molds. The theoretical issue of this article is specifically the operation of the selvagem name/denomination within a counteridentification. This is done by a methodological course that is inscribed in the materialist theory of discourse and which considers the gestures of interpretation as a theoretical device. The materiality involves an interview granted by the precursor of the movement, Douglas Diegues, in 2012. It is interpreted as naming, in this perspective of resistance, also identifies.

KEYWORDS: Portunhol Selvagem; Discourse Analysis; Resistance; Douglas Diegues.

\footnotetext{
${ }^{1}$ Doutoranda em Estudos Linguísticos pela UFSM. Professora de redação do Curso Preparatório Caxias.
} 


\section{Introdução}

O sujeito, da perspectiva da Análise de Discurso de linha francesa (doravante AD), só se constitui como tal ao ser interpelado ideologicamente, originando uma identificação. Entretanto, no interior desta ideologia, podem ocorrer processos de contraidentificação e desidentificação, conforme as modalidades de funcionamento subjetivo postuladas por Pêcheux ([1975]1997), em relação ao dominante estabelecido, isso propicia tomadas de posição de resistência por parte dos sujeitos. O sujeito contraidentificado encontra, nas próprias falhas, desvios e brechas do sistema, maneiras de resistir à ideologia dominante; contudo, isso não se dá sem consequências, há punições a esse resistir, o que pode empurrá-lo a uma condição marginal ou a um processo de naturalização provocado pela reação do sistema.

O modo como se mobiliza a língua, como se discursiviza, determina os sentidos. Tal processo, com isso, implica nomear certas instâncias, objetos e sujeitos, o que não os classifica; mas, antes, identifica (RANCIÉRE, 1994), originando nuances da produção de sentidos e indicando de que lugar o sujeito fala. Há sempre uma relação entre o acontecimento histórico e o acontecimento discursivo da nomeação. Ao se considerar o processo do nome, é preciso levar em conta também a presença de toda a sua historicidade, como memória de sentidos.

O percurso teórico-argumentativo apresentado até aqui, ao abordar sujeito, ideologia e discurso, contempla o presente trabalho, que tem como objeto a nomeação e a denominação portunhol selvagem. Este trata-se de um movimento cultural que emprega um portunhol escrito para compor sua arte literária, ainda, ele tem a específica nomeação de "selvagem", uma vez que é diferente do portunhol comum, não só por ser escrito, mas também por mobilizar, além de português e espanhol, línguas indígenas, francês, inglês, italiano, entre outras, conforme a criação do autor (ALBUQUERQUE, 2014; DIEGUES, 2016²). É uma língua tida como de fronteira, híbrida, que não se dobra às regras gramaticais normativas que são conhecidas, erigindo como manifestação artística de resistência. Logo, o conceito de língua para tratá-la não se dá em relação a um sistema normativo e estrutural, nos moldes totalitários já estabelecidos, via uma idealização; mas, antes, é preciso se colocar na esfera do materialismo histórico e da $\mathrm{AD}$, que tem em sua concepção o fato de as línguas serem

\footnotetext{
2 https://malhafinacartonera.wordpress.com/2016/03/09/transdeliracao-selvagem/ acesso em 24 mar 2017
} 
também processos sociais, as quais se estabelecem discursivamente pela sua relação com a história no processo de constituição dos sujeitos e dos sentidos. A ideologia, como prática significante, aparece como efeito desta relação (FERREIRA, 2003).

Uma vez que o portunhol selvagem se apresenta como resistência a um sistema ideológico que não o considera detentor de gramática ou cabível em uma norma, a questão teórica deste trabalho é o funcionamento do nome portunhol selvagem no interior desta contraidentificação. Isso será feito por um percurso metodológico que se inscreve na $\mathrm{AD}$ e que considera os gestos de interpretação como um dispositivo teórico. A materialidade envolve uma entrevista concedida por Douglas Diegues, precursor do movimento cultural, publicada em 2012, fazendo-se o gesto de interpretar como o nomear e denominar, nessa perspectiva de resistência, também identifica.

\section{Portunhóis}

A organização política dos Estados nacionais marca os espaços em que as línguas funcionam historicamente. Isso confere uma importância fundamental a noções como língua nacional, língua oficial, que aparecem dividindo as línguas. No entanto, a relação entre falantes e línguas não se reduz a esse modo de representação. Os falantes mobilizam suas línguas por esta determinação Estado-Nação, mas também por diversas outras (GUIMARÃES, 2007). A língua portuguesa no Brasil se dá nesse transporte para um novo espaço/tempo, para novas situações comunicativas. E essa língua brasileira experimenta mais atualização, ainda contemporaneamente, em seus contatos fronteiriços, conflituando-se com a noção de nacionalidade angariada em todo um processo de independência quanto à língua portuguesa do Brasil. Existem operações discursivas, coordenações específicas pelas quais o acontecimento do dizer mobiliza a língua em textualidades particulares, como na fronteira, proporcionando a formação de um espaço de construção linguística.

No caso do Brasil e dos países vizinhos, especialmente, efetivam-se múltiplas situações comunicacionais de um portunhol falado. Essa comunicação falada em portunhol é bastante característica para as gerações que viveram e vivem nessas fronteiras de entrelaçamento de povos e culturas, o que tem acontecido nas últimas décadas é um outro movimento, uma atualização discursiva: o portunhol sendo escrito poeticamente, à margem da produção cultural vigente, mas organizado e difundido - sendo denominado por seus autores de portunhol selvagem. 
Há mais de um sentido em torno deste encontro entre português e espanhol. Pejorativamente, portunhol acaba por se referir a uma mistura errônea das duas línguas, produto do desconhecimento ou de uma aprendizagem deficiente. Neste sentido depreciativo, configurase como língua inacabada, gerada pela ignorância do falante (ATTI, 2013). É possível distinguir, pelo menos duas acepções de portunhol: portunhol como a interlíngua oriunda da falha e portunhol como língua comunicacional própria da fronteira. Esta é nascida espontaneamente do convívio entre falantes do português e do espanhol, não se deixa domar por regras gramaticais, nem se limita a um léxico estruturado. Caracteriza-se pela oscilação entre o português e o espanhol, mantendo-se permanentemente aberta, sem se estruturar segundo um código previamente estabelecido (VARGAS, 2011).

O portunhol selvagem, por sua vez, aparece como uma terceira vertente, é uma espécie de hibridismo linguístico livre, que vive na fronteira também livre. Ele se apropria do vocabulário de várias línguas ao mesmo tempo em que não se limita a nenhuma delas e está em constante efervescência e movimento. O poeta Douglas Diegues, nascido no Rio de Janeiro e radicado em Ponta Porã - que constitui uma área de fronteira com a cidade Pedro Juan Caballero, capital do departamento de Amambay, no Paraguai -, é considerado, hoje, o principal expoente do portunhol selvagem, um movimento que reúne artistas latinoamericanos que utilizam uma linguagem amalgamada, encontro de português, espanhol, línguas indígenas, com presença de francês, inglês, entre outras línguas. Esses artistas, como resistência, apresentam, em seu discurso, um modo de expressão anárquico que parece estar acima das fronteiras geográficas e culturais, semelhante ao funcionamento da língua forjada para uma nação. Este trabalho problematiza o fato de o portunhol selvagem erigir, antes e a despeito das discussões de língua e gramatização, como uma questão de militância poéticocultural.

O portunhol selvagem, como processo de escritura não é da ordem do categorizável, é selvagem como estética literária de resistência, não se encaixa nas categorias da gramática normativa e em sua concepção de língua. Ao mesmo tempo, a escrita artística em portunhol selvagem é responsável por ampla difusão e consolidação do movimento, conferindo-lhe outro status, outra hierarquia social e política. Isso demonstra que a língua e seus sentidos não são controláveis.

\section{Nomear e denominar: um posicionamento discursivo}


A nomeação é uma das questões centrais quando o debate é a relação entre linguagem e realidade. Servir-se de um nome é como estabelecer um pacto, um compromisso de que aquilo existe no real sendo, deste modo, verdade. Nomear implica também designar alguma coisa e isso, segundo Platão (2001), significa dar informação da coisa designada a outros. Ou seja, é distinguir uma coisa entre outras conforme sua constituição. Com isso, nomear é também um ato de identidade, promove a identidade e separa através da diferenciação.

Consoante Rancière (1994), o social designa a não relação com o original. Ele designa o desvio das palavras em relação às coisas ou, mais exatamente, o desvio das nomeações às classificações: "um nome identifica, ele não classifica" (p.43). Se o nome é a base para que a identidade exista, é ele quem diferencia coisas e seres. Afirmar-se algo ou se identificar sob um nome inclui negar e esconder vários outros que de imediato não aparecem. Essa negação e o que está escondido não estão dados, a priori, junto com o nome. Além disso, as posições de quem nomeia e do que é nomeado devem ser obedecidas, e elas importam quem tem poder e autoridade para nomear e quem, ou o que, está subordinado a esse poder em determinada condição de produção (STRAIOTTO MOREIRA, 2010). A nomeação tem força, contudo somente o sujeito com o respaldo necessário para isso terá validade para nomear. Uma falha na nomeação e na posterior designação pode estar nos gestos de interpretação, pois se corre o risco de atribuir-lhe sentido a partir de determinado sistema de nomeação e predicação.

Orlandi (2002) introduz o conceito de acontecimento linguístico para nomear, especialmente em casos de colonização, essa relação do lugar discursivo e da língua nacional, sempre considerando que toda interpretação de um lugar discursivo necessita levar em conta a consciência linguística da época considerada e a forma como a questão é apresentada nesse período. Devem-se compreender os acontecimentos discursivos dos nomes como uma interpretação feita de determinado lugar discursivo. Há sempre uma relação existente entre o acontecimento histórico e o acontecimento discursivo da nomeação, uma vez que ambos acontecimentos estão constitutivamente relacionados.

A nomeação não concerne apenas ao referencial, mas também produz outros sentidos, já que, por intermédio dela, outorgam-se estados, predicações, características, dando origem a novos e outros sentidos além dos já existentes e afetando o sujeito em sua identidade, em seu processo de identificação. Nomear não atribui mero sentido referencial ao que é nomeado, mas identifica-o, conferindo-lhe um lugar, afetado por uma ideologia, aquela que o interpelará no processo de identificação.

Consoante pontua Pêcheux ([1975]1997), o funcionamento da Ideologia em geral como interpelação dos indivíduos em sujeito se realiza através do complexo das formações 
ideológicas e fornece a cada sujeito sua realidade, enquanto "sistema de evidências e de significações percebidas-aceitas-experimentadas".

A interpelação do indivíduo em sujeito de seu discurso se efetua pela identificação (do sujeito) com a formação discursiva que o domina (isto é, na qual ele é constituído como sujeito): essa identificação, fundadora da unidade (imaginária) do sujeito, apoia-se no fato de que os elementos do interdiscurso que constituem, no discurso do sujeito, os traços daquilo que o determina, são reescritos no discurso do próprio sujeito (PÊCHEUX, 1997, p.163).

Segundo Guimarães (2005), para nomear, o sujeito deve estar inscrito em um espaço discursivo afetado por uma regularidade específica, permeado por uma formação discursiva, que o possibilita falar de determinada posição de sujeito. É necessário considerar que há uma configuração própria segundo a qual o nome possui sua historicidade de sentidos, identificação que se dá a uma formação discursiva dominante. Ao trabalhar o conceito de designação (GUIMARÃES, 2005) em condições de produção de resistência, verifica-se que tal processo se dá na medida em que coloca em confronto duas posições-sujeito no interior de uma formação discursiva. É esse confronto que demarca os objetos, faz com que a mudança de posição-sujeito recorte uma outra memória de dizer, o que significa de forma distinta um nome de outro. As mesmas palavras, expressões e proposições mudam de sentido ao passar de uma posição-sujeito a outra. Assim, é por meio da designação que se constrói o objeto do qual se fala, remetendo sempre os sentidos ao real, afetado pelo simbólico. Desse modo, a materialidade do objeto constrói-se em relação com a memória, com o interdiscurso.

Infere-se, então, uma relação instável entre objeto e discurso, visto a não estabilidade dos discursos, pois neles há o cruzamento de várias posições-sujeito, que representam as formações discursivas que estabelecem um embate, o que expõe o objeto à diferença. Conforme recorte de Orlandi (2002), o português transportado para o Brasil foi, pelo imaginário, estabelecendo outra realidade para a relação palavra-coisa, a operação referencial nome-coisa deu lugar, pela gramatização, à atividade conceptual nome-nome (dicionário). $\mathrm{O}$ portunhol (selvagem ou não), de certo modo, faz o caminho inverso, rememorando a importância da materialidade histórica do próprio território.

\section{Portunhol e Selvagem: gestos de interpretação}

As discussões metodológicas deste trabalho são definidas pelo paradigma materialista histórico, mobilizando conceitos da $\mathrm{AD}$, uma vez que o seu objeto de estudo - a nomeação e 
denominação portunhol selvagem - resulta de uma leitura teórica, determina-se a partir de relações históricas, sociais e culturais, ou seja, relações construídas discursivamente. Na AD, mais do que o sujeito, interessam as posições-sujeito, uma vez que o sujeito é pensado discursivamente como uma posição entre outras. Não há, portanto, uma forma de subjetividade, mas um lugar que o sujeito ocupa para ser sujeito do que diz, os processos discursivos vão se desenvolver pelo sujeito, mas não têm nele sua origem.

Em sua relação com a língua, o sujeito do discurso estabelece um processo de constituição recíproca, constituindo-se e constituindo-a no cerne de acontecimentos histórico-sociais. É papel do gesto de interpretação realizar essa relação do sujeito com a língua na produção dos sentidos. Assim como ocorre com o sujeito, Ferrerira (2003) afirma que o sentido nunca é individual, nem apresenta-se como já produzido. O discurso é o objeto que permite observar as relações entre ideologia e língua, bem como os efeitos do jogo da língua na história e os efeitos desta na língua. Considera-se neste trabalho uma noção de língua dotada de natureza instável, heterogênea por formação e contraditória: a língua é lugar material de realização dos processos discursivos, em que se manifestam os sentidos:

\begin{abstract}
O sistema da língua é, de fato, o mesmo para o materialista e para o idealista, para o revolucionário e para o reacionário, para aquele que dispõe de um conhecimento dado e para aquele que não dispõe desse conhecimento. Entretanto, não se pode concluir, a partir disso, que esses diversos personagens tenham o mesmo discurso: a língua se apresenta, assim, como base comum de processos discursivos diferentes, que estão compreendidos nela na medida em que, os processos ideológicos simulam os processos científicos (PÊCHEUX, 1997, p. 91).
\end{abstract}

A posição de um texto é sempre a partir de uma posição ideológica e política. Quando o sujeito pode resistir a uma ideologia dominante? Nesse momento, entra em jogo o embate entre a interpelação ideológica e a resistência. Efeitos contraditórios fazem parte do mesmo processo; a resistência, então, é quando a contradição se torna mais forte no processo de assujeitamento. A contraidentificação se dá ainda dentro da ideologia. Para ser contra, é preciso estar dentro, conhecer. Semelhante ao que afirma Rancière (1994, p.38): “Todos os que não têm lugar para falar se apoderarão destas palavras e destas frases, destas argumentações e destas máximas, para constituir para a subversão um corpo novo de escrita”. É permitido resistir, mas o sujeito é punido. Como no caso do portunhol selvagem, em que fica à margem do sistema editorial vigente, sendo publicado via editoras cartoneras - modo de produção e distribuição de livros feitos com capas de papelão e vendidos a um preço módico. A resistência, por ser um processo fluido, apresenta também uma tendência de naturalização. 
Por exemplo, o caso de uma eventual gramatização do portunhol, a qual tiraria o direito de problematização, porque traria igualdade, e igualdade não produz revolução e resistência.

O corpora analisado a seguir é uma entrevista ${ }^{3}$ concedida por Douglas Diegues à Revista abehache, em 2012, a respeito do portunhol selvagem, intitulada: "Corregirlo sería matarlo" Entrevista a Douglas Diegues, poeta em "portunhol selvagem miri michi”. Além da nomeação portunhol, que implica o uso conjunto de português e espanhol, há a denominação selvagem (já mencionada neste trabalho) e mais uma: michi miri, que traduzido do guarani indica algo humilde, menor, já começando a movimentar também certa postura que perpassa a posiçãosujeito de quem escolhe o portunhol selvagem como manifestação estética. Uma observação: o autor responde todas as perguntas em portunhol selvagem, e assim será aqui transcrito.

Ao caracterizar o portunhol Selvagem, Diegues afirma: “El portunhol michi miri tem uma gracia que impacta: es bizarro, feo, bello, contudente, desprendido, menor que menor, dibertido, alucinógeno, anacronico, selvagem, civilizadíssimo, delirante, en fin...", tal posicionamento demonstra uma não preocupação com o que é certo, normativo, que se coloca de uma maneira apenas - o esperado pela ideologia dominante. Esse modo de mobilizar língua não se quer uma coisa ou outra, quer tudo ao mesmo tempo, os contrários encontrados, uma posição voluntariamente caótica (uma vez que o efeito de evidência mascara o caráter material do sentido) em meio ao totalitarismo.

A explicação da denominação selvagem consoante Diegues:

La primeira lengua en la kual me he expressado quando aprendi a falar non fue el portugues nim el español nim lo guarani, mas sim el portunhol de indole selvática. Por que selvagem? Porque que brota de las selvas de mio corazon y de los corazones de los habitantes de las selvas desconocidas de la frontera del Brasil com el Paraguay. Quanto a lo de la potencia, es muy original el portunhol selvagem, es uma lengua neoantigua, que existe como habla y escritura, pero non como idioma y me permite dizer coisas antiguas de forma nueba, además de permitirme hacer poesia ou prosa com um power bem mais amplo de expressiónes que se escribiera limitado al português brasileiro ou al castellano paraguayo apenas, una potencia que consiste, obviamente, en selbagem y hermosíssima liberdade de lenguagem (DIEGUES, 2012, grifo meu).

Percebe-se aí o funcionamento da nomeação e da denominação em um processo de resistência. No interior da ideologia dominante a qual é assujeitado e a qual conhece, o sujeito não se identifica, em seguida se contraidentificando e fazendo funcionar sua posição de resistência. Essa posição-sujeito se caracteriza por contestar, questionar e revoltar-se contra as evidências ideológicas da formação discursiva à qual está assujeitada (BECK, 2010). Pêcheux

\footnotetext{
${ }^{3}$ http://revistaabehache.com.br/index.php/abehache/article/view/57/56 Acesso em 24 Mar 2017
} 
([1975],1997) definiu esta modalidade como um discurso-contra (ou contradiscurso): o mau sujeito por definição operaria uma contraidentificação em relação ao bom sujeito, mas não se desvencilharia de todo da matriz de sentidos das formações ideológicas dominantes.

Antes mesmo de o portunhol selvagem existir e se fortalecer como fala e escrita, ou de ser considerado não idioma, pelo seu nome e por sua denominação perpassam marcas de resistência. Selvagem não porque não civilizado, longe do ideal; selvagem por antagonismo/resistência, porque se quer livre, original - elementos que a civilização retiraria ao normatizar tudo no interior de sua ideologia. O selvagem aqui sabe-se incorreto em relação à estrutura vigente e quer sê-lo, resistindo, fugindo da naturalização: "Politicamente, es um negócio incorrecto. Sua naturaleza escurridiza non se deixa domesticar por uma hegemonia absoluta sobre el resto de los domínios teóricos ou akademicos” (DIEGUES, 2012).

A não identificação primeira desliza no discurso do sujeito: "mio português brasileiro ou fronterizo ou paraguaio, como sea, sempre me ha parecido um negócio muito falso. Entón empezei a escreber em portunhol selvagem. Y me senti muy bien" (DIEGUES, 2012, grifo meu). Antes de assumir a posição de resistência, no interior da ideologia dominante, há esse questionamento em relação às normas impostas na fronteira, as quais são distantes da historicidade do sujeito que vive ali. Isso é seguido de um processo de contraidentificação, que produz um discurso-contra (PÊCHEUX [1975]1997), ao localizar seu lugar numa escrita que reúne todas as suas falas, o qual é rotineiro, mas vive como se não existisse, por não ser oficial. Daí o início da resistência, ao fazer o portunhol da arte existir. E circular. O movimento de (re)posicionamentos subjetivos - que parte da identificação, passa pela contraidentificação e pode chegar até a desidentificação - se configura como um processo. Uma das modalidades de subjetivação propostas por Pêcheux ([1975]1997), a da contraidentificação, seria um primeiro movimento necessário para a constituição do mecanismo da desidentificação, como uma tomada de posição não subjetiva, que permitiria escapar às evidências da ideologia dominante, possibilitando que o sujeito desta modalidade lute contra as causas que o determinam.

Corregírlo sería matarlo. Gramatificarlo equivale a suicidarlo. No es competitivo, non quere ser, simplesmente lo es, com su mambo irracional, su liberdad sem limites. Es local, es internacional, es transnacional, es literario, es post literario. Es uma neo lengua, a falta de um termino mejor o peor, desregulada $y$ desregularizante. Tiene una gracia que molesta y encanta a la vez. Es menos literario y mais literario. Y non cuenta com apoyo financeiro estatal, editorial, midiatico, para gozar de uma situacione pribilegiada respecto a los otros modos de entender, hacer, vivir la literatura de manera transgressora e insurrecta... Cada estado tiene sua literatura ofiziale. Y el portunhol selvagem es uma literatura non- 
oficial que pode ser situada, temporariamente, nesse lugar ninguno, entre ambos lados de las fronteras (DIEGUES, 2012).

Isto posto, portunhol selvagem passa a ser a língua de circulação nesse novo espaço que se constitui, é uma base que tem sua organização, sua gramática - uma vez que é entendível -; porém, a partir disso, procura fluir longe dos padrões estabelecidos: "El portuñol sauvage es la base, la base antropofágica, neo antigua, que puede incorporar, además del guarani, palabras de otras lenguas", ademais, "es uma delícia y uma dádiva la gracia de poder rechazar padronizaciones, ortografias fixas, ortodoxías fonicas, ortopedías petroglíficas, em beneficio de la liberdade selvagem" (DIEGUES, 2012, grifo meu).

O portunhol, além de língua de fronteira, é também selvagem, uma vez que sua denominação é posição de resistência quanto ao sistema ideológico que o exclui. O sujeito que o denomina não só vive em uma fronteira geográfica, mas também na fronteira das línguas consideradas oficiais e em um lugar social que se opõe à normatização literária, às políticas editoriais oficiais. O preço disso é a publicação à margem das obras em portunhol selvagem, seu funcionamento por meio de editoras alternativas cartoneras e seu não reconhecimento pelo Estado. Perguntado se o portunhol Selvagem é mero gozo, Diegues afirma ser um gozo como postura pós-política, sabendo-se longe das regalias do sistema oficial.

Yo intento hacer del portunhol selvagem la base para fazer uma literatura propia, non aburrida, que los lectores (que non sei que son nim quem serán) puedan ser disfrutar de este y de los outros lados de las fronteras. A la vez, esta experiencia, este goce como postura post politica, post nazionale, post real, es um riesgo que decidi correr, sacrificando todas las regalias que te rodean cuando escribis nel contexto de uma lengua oficial, com apoyo estatal, sistema de premiaciones, promociones nacionales et alia... (DIEGUES, 2012).

Consoante afirma Diegues $(2016)^{4}$, mais que importante, é algo prazeroso escrever numa língua que não existe como idioma, mas existe como fala e como escritura, é como inventar uma língua dentro das línguas em que se está tradicionalmente inscrito, é também um gesto político: não escrever como um bom aluno obediente à língua oficial do Estado, "es como escrever en la tierra de ninguém, de lo indeterminado, de lo imprevisível. De modo que penso que escrever num idioma híbrido tem mais delícias que importâncias”.

Dentro do proposto a respeito de gramatização por Auroux (1992), não há um processo de gramatização quanto ao portunhol selvagem e tampouco se quer tê-lo, pois não há um instrumento linguístico, há apenas uma estabilidade de compreensão por conta das múltiplas

\footnotetext{
${ }^{4}$ https://malhafinacartonera.wordpress.com/page/3/ Acesso em 21 de jun 2016.
} 
línguas que o compõem e pela sua fluidez comunicativa. Entretanto, ainda que tal hibridismo dialetal não seja reconhecido como língua - nos moldes totalitários e rarefeitos estabelecidos até então -, trata-se de uma legítima manifestação estética e cultural, seus recursos estéticos também são parte do que o torna entendível. Não há política linguística sem gramática e a forma gramática define a dinâmica das políticas linguísticas, mas o conceito de gramática não é único. O hibridismo dialetal aqui referido também possui sua gramática, a qual é reconhecida por seus falantes, fazendo dela uma língua entendível, ainda que fora do ponto de vista normativo já conhecido.

Como afirma Rancière (1994), resta, ainda, o poder congregador da língua, e dos jogos que ela autoriza, o poder de um discurso sempre suscetível de fazer entrar na sua comunidade aqueles que o traçado de seu círculo exclui.

\section{Conclusã̃o}

Sendo o portunhol selvagem um movimento de resistência a um sistema que não o considera dentro da norma ou detentor de gramática, este trabalho buscou mobilizar a questão do funcionamento do nome portunhol selvagem no interior desta contraidentificação. A partir das palavras de Douglas Diegues, representando a posição-sujeito defensora e parte deste movimento cultural, verificou-se que, nas falhas, desvios e brechas do sistema, funcionam maneiras de resistir à ideologia dominante; havendo, no entanto, consequências a esse resistir, que, no caso do Portunhol Selvagem, deixa o sujeito e sua língua à margem de um sistema literário oficial ao mesmo tempo em que tenta naturalizá-lo,

O modo como o sujeito escolheu mobilizar a língua, ou seja, discursivizar, determinou os sentidos e o lugar de onde este fala, identificando o nome Portunhol e a denominação Selvagem como marca linguística de resistência social. Isso corrobora a relação constitutiva entre o acontecimento histórico e o acontecimento discursivo da nomeação. Ao se considerar o processo do nome, é preciso levar em conta do mesmo modo a presença de toda a sua historicidade, como memória de sentidos.

Portunhol selvagem - nome e denominação - corresponde, então, a um dos resultados da contraidentificação ideológica na fronteira entre Brasil e países vizinhos, marcada na e pela língua. Trata-se da base de um movimento cultural que emprega uma língua própria para compor sua arte literária, inserindo-a em uma cultura letrada que, concomitantemente, quer as portas fechadas ao que não é oficial. A língua fronteiriça da arte se universaliza ao, por escolha, não se render às regras gramaticais normativas que são conhecidas, erigindo como 
manifestação artística de resistência. A escrita artística em portunhol selvagem oportuniza difusão e consolidação do movimento, conferindo-lhe novo status, nova hierarquia social e política, as quais carregam a difusão de seu nome. Novamente, é possível afirmar que a língua e seus sentidos não são controláveis, nem mesmo a ideologia dominante pode anular o poder da identidade, seja ela afetiva, seja cultural, seja social. Contudo, conforme defende Beck (2010), a hegemonia da ideologia dominante somente é abalada pelo avanço do processo de transformação com a consequente alteração nas relações de forças sócio- econômico-políticas e ideológicas. O caráter de não oficializado é importante ao movimento, pois marca uma posição de resistência em relação ao centro, marca um novo lugar, o entre-lugar dessa língua que procura avançar.

\section{REFERÊNCIAS}

AUROUX, S. A revolução tecnológica da gramatização. Trad. Eni P. Orlandi. Campinas, SP: Editora da Unicamp, 1992.

ATTI, F. D. Considerações acerca do movimento do Portunhol selvagem: o paradigma da osmose e a resistência cultural. Babilónia: Revista Lusófona de Línguas, Culturas e Tradução, 2013.

BECK, M. Aurora Mexicana. Processos de resistência-revolta-revolução em lutas populares da América Latina: O exemplo do discurso zapatista. Tese (Doutorado). Santa Maria, RS: UFSM, 2010.

DIEGUES, D. "Corregirlo sería matarlo" - Entrevista a Douglas Diegues, poeta em "portunhol selvagem miri michi”. In: GASPARINI, P; OLMOS A.; CELADA, M. abehache Revista da Associação Brasileira de Hispanistas. Ano 2, nº 2, $1^{\circ}$ semestre, 2012.

Translideração Selvagem. São Paulo: 2016. Disponível em:

https://malhafinacartonera.wordpress.com/2016/03/09/transdeliracao-selvagem/ Acesso em 24 de mar de 2017.

FERREIRA, M.C.L. O caráter singular da língua na Análise do Discurso. Organon. v. 17, n. 35. Instituto de Letras - UFRGS, 2003

GUIMARÃES, E. Semântica do acontecimento: um estudo enunciativo da designação.

Campinas, SP: Pontes, $2^{\mathrm{a}}$ Ed, 2005.

Política de línguas na linguística brasileira - Da abertura do curso de

Letras ao Estruturalismo. In: ORLANDI, Eni P. (org.). Política linguística no Brasil.

Campinas, SP: Pontes Editores, 2007.

ORLANDI, E.P. Língua e conhecimento linguístico: para uma história das ideias no Brasil.

São Paulo: Cortez, 2002.

PÊCHEUX, M. Semântica e Discurso: Uma Crítica à Afirmação do Óbvio. Tradução de Eni Pulcinelli Orlandi, Lourenço Chacon Jurado Filho, Manoel Luiz Gonçalves Corrêa e Silvana Mabel Serrani. 3. Ed. Campinas. Ed. Unicamp, 1997.

PLATÃO. Diálogos. Teeteto Crátilo. 3. Ed. Belém: UFPA, 2001.

STRAIOTTO MOREIRA, T. O ato de nomear - da construção de categorias de gênero até a abjeção. In: XVI Congresso Nacional de Linguística e Filologia, 2010, Rio de Janeiro. 
Cadernos do CNLF. Rio de Janeiro: Instituto de Letras da UERJ, 2010. v. 14. p. 29142926.VARGAS, F.A. Fronteiras literárias: as línguas ibéricas e o portunhol. Anais do VI Congresso Internacional Roa Bastos, Foz do Iguaçu, 28-30 Set. 2011. Disponível em <http://www.nelool.ufsc.br/simposio2011/fronteiras_literarias.pdf >. Acesso em 21 Jun. 2016.

Recebido em: 29/03/2017. Aceito em: 04/06/2017. 